\title{
Effect of Pour Point Depressants Combined with Dispersants on the Cold Flow Properties of Biodiesel-Diesel Blends
}

\author{
Baoting $\mathrm{Su}^{1}$, Lulu Wang ${ }^{1}$, Yuan Xue ${ }^{2}$, Jincan $\mathrm{Yan}^{2}$, Zhenbiao Dong ${ }^{2}$, Hualin $\mathrm{Lin}^{2}$, and \\ Sheng $\operatorname{Han}^{2}$ \\ ${ }^{1}$ Shanghai University of Engineering Science \\ ${ }^{2}$ Shanghai Institute of Technology
}

October 9, 2020

\begin{abstract}
Poor cold flow property is a major issue that hinders the application of biodiesel-diesel blends. In this work, a series of methacrylate-benzyl methacrylate-N-vinyl-2-pyrrolidone terpolymers (RMC-MB-NVP, R= C12, C14, C16, C18) was synthesized and used as the pour point depressants (PPDs) for waste cooking oil biodiesel blends. To further improve their depressive effects, dispersants, including Tween (40,60, and 80), Span (40,60, and 80), phthalic acid esters (PAEs), and fatty alcohol polyoxyethylene ether (FAPE; FAPE 5, FAPE 7, and FAPE 9), were optimized and combined with the C14MC-MB-NVP terpolymers. The effects of C14MC-MB-NVP terpolymers and combined PPDs (PPDC) on the cloud point (CP), cold filterplugging point (CFPP), and pour point (PP) of biodiesel blends were studied. Here, results showed that the presence of dispersants can efficiently enhance the solubility and dispersibility of polymeric PPDs in biodiesel blends; thus, the PPDC presents better depressive effects. Among of them, C16MC-MB-NVP (5:1:1) combined with FAPE 7 dispersant at 4:1 mass ratio (PPDC-FAPE 7) showed the best synergistic effect, and the CP, CFPP, and PP of B20 treated with 2000 ppm PPDCFAPE 7 decreased by 4,10 and $19{ }^{\circ} \mathrm{C}$, respectively. Moreover, differential scanning calorimetry, polarizing optical microscope and rheological analyses were performed to rationalize the action mechanism of these PPDs and dispersants in biodiesel blends.
\end{abstract}

Effect of Pour Point Depressants Combined with Dispersants on the Cold Flow Properties of Biodiesel-Diesel Blends

Baoting Su ${ }^{1,2}$ [?] Lulu Wang ${ }^{1,2}$ [?] Yuan Xue ${ }^{2,3, *}$ [?] Jincan Yan $^{2}$ [?] Zhenbiao Dong ${ }^{2}$ [?] Hualin $\operatorname{Lin}^{2, *}[?]$ Sheng $\operatorname{Han}^{1,2, *}$

${ }^{1}$ School of Chemistry and Chemical Engineering, Shanghai University of Engineering Science, Shanghai, 200336, China

${ }^{2}$ School of Chemical and Environmental Engineering, Shanghai Institute of Technology, Shanghai, 201418, China

${ }^{3}$ School of Materials Science and Engineering, University of Shanghai for Science and Technology, Shanghai, 200093, China

* Corresponding author: Fax: +86-021-60873565, Tel: +86-02160873560; Email address: sit_xueyuan@163.com (Yuan Xue), 64061787@qq.com (Hualin Lin), hansheng654321@sina.com (Sheng Han).

\section{Abstract}

Poor cold flow property is a major issue that hinders the application of biodiesel-diesel blends. In this work, a series of methacrylate-benzyl methacrylate-N-vinyl-2-pyrrolidone terpolymers (RMC-MB-NVP, $\mathrm{R}=$ $\mathrm{C}_{12}, \mathrm{C}_{14}, \mathrm{C}_{16}, \mathrm{C}_{18}$ ) was synthesized and used as the pour point depressants (PPDs) for waste cooking oil 
biodiesel blends. To further improve their depressive effects, dispersants, including Tween (40,60, and 80), Span (40,60, and 80), phthalic acid esters (PAEs), and fatty alcohol polyoxyethylene ether (FAPE; FAPE 5, FAPE 7 , and FAPE 9), were optimized and combined with the $\mathrm{C}_{14} \mathrm{MC}-\mathrm{MB}-\mathrm{NVP}$ terpolymers. The effects of $\mathrm{C}_{14} \mathrm{MC}-\mathrm{MB}-\mathrm{NVP}$ terpolymers and combined PPDs (PPDC) on the cloud point (CP), cold filter-plugging point (CFPP), and pour point (PP) of biodiesel blends were studied. Here, results showed that the presence of dispersants can efficiently enhance the solubility and dispersibility of polymeric PPDs in biodiesel blends; thus, the PPDC presents better depressive effects. Among of them, $\mathrm{C}_{16} \mathrm{MC}-\mathrm{MB}-\mathrm{NVP}$ (5:1:1) combined with FAPE 7 dispersant at 4:1 mass ratio (PPDC-FAPE 7) showed the best synergistic effect, and the CP, CFPP, and PP of B20 treated with 2000 ppm PPDC-FAPE 7 decreased by 4, 10 and $19{ }^{\circ} \mathrm{C}$, respectively. Moreover, differential scanning calorimetry, polarizing optical microscope and rheological analyses were performed to rationalize the action mechanism of these PPDs and dispersants in biodiesel blends.

\section{Keywords}

Cold flow properties [?] Biodiesel-diesel blends [?] Pour point depressants [?] Dispersants [?] Combined pour point depressants

\section{Introduction}

Biodiesel usually contains various of fatty acid methyl esters (FAME), which are derived from vegetable oils, animal fats, or waste cooking oil (Chen et al., 2010; Joshi et al., 2007; Lv et al., 2013; Madihalli et al., 2016; Cao et al., 2014). It is an eco-friendly liquid fuel because it is biodegradable and less harmful to the environment (Altaie et al., 2015; Vedharaj et al., 2014; Chiu et al., 2004; Moser et al., 2010). The use of biodiesel from waste cooking oil (BWCO) as engine fuel can reduce the consumption of petroleum-based diesel, thereby reducing waste oil emissions and improving the environment (Xue et al., 2016; Wang et al., 2015; Cao et al., 2014 ). However, the unpleasant cold flow properties always prevent biodiesel fuels from being directly added to diesel engines (Xue et al., 2016; Zheng et al., 2014; Moser, 2014; Feng et al., 2014).

To solve this problem, many countries worldwide have used biodiesel by blending with petro-diesel. Definition and detailed specifications of biodiesel blends are outlined in many foreign countries. The United States allows the use of B6 to B20 blends, and the European Committee for Standardization specifies a maximum of 7 vol.\% biodiesel mixed into petro-diesel (Moser, 2012; Sharafutdinov et al.,2012; Giraldo et al., 2013). Indonesia and Argentina have increased the allowable biodiesel blends to B30 and B20, respectively. In China, the national standards on B5 have been published, and the local standards have been raised to B20. Although the low-temperature performance of biodiesel can be improved to some extent by blending, the effect still cannot satisfy the expectations. At lower temperature, a large amount of saturated fatty acid esters causes the biodiesel blends to crystallize ansd gel more rapidly than petro-diesel, thereby limiting their application (Cao et al., 2014; Ma et al., 2015). On the other hand, due to China's vast territory, biodiesel still has limitation in the application of cold flow performance in high latitude areas.

The method of adding pour point depressants (PPDs) are commonly used to improve the low-temperature performance of biodiesel blends (Liu et al., 2019; Xu et al., 2018; Zhou et al., 2016). Polymethyl acrylate (PMA) has recently attracted attention due to its excellent effects (Chastek, 2011; Zhao et al., 2018). In a previous research, PMA was synthesized and used to improve the cold flow ability of diesel. The results showed that PMA has an excellent depression effect on diesel (Umoruddin et al., 2018; Soliman et al., 2018; Lemos et al., 2018; Wang et al., 2014). Unfortunately, in biodiesel, the single PMA copolymer often showed poor results. PMA has different effects on petro-diesel and biodiesel because of their difference in composition. Furthermore, PMA are viscous copolymers, which lead to insufficient dissolution of biodiesel; thus, the final effect of PPD in biodiesel is influenced.

Dispersants of polar groups, characterized by strong oil solubility, low price, and low dosage, can be combined with copolymer depressants to form highly effective combined PPDs (PPDCs) to improve the cold flow ability of fuel. Thus far, some studies have mentioned the combination of PPDs and dispersants. Xue et al. (2016) added PMA with Span, Tween, and PEG dispersants to BWCO. When PMA is mixed with Span 80 at a mass ratio of 2:1, and the added concentration is $5000 \mathrm{ppm}$, the CFPP is decreased by $7 \operatorname{degC}$. However, the 
previous literature focused more on the mixing between copolymer PPDs. At present, the combination of dispersants and PPDs to improve the performance of biodiesel is still a challenge and needs further research. Most dispersants reported in the literatures have low molecular weight and high activity laboratory-prepared copolymers (Maithufi et al., 2011; Soni et al., 2008; Papke et al., 1991; Biswell et al., 1955; Lin et al., 2020). These dispersants not only increase the experimental workload and difficulty, but also the cost. Therefore, Tween, Span, phthalic acid esters (PAEs) and fatty alcohol polyoxyethylene ether (FAPE) were selected as dispersants to be mixed with PPDs to improve the cold flow properties of biodiesel blends in this study.

In this work, a series of methacrylate-benzyl methacrylate-N-vinyl-2-pyrrolidone (RMC-MB-NVP, $\mathrm{R}=\mathrm{C}_{12}$, $\left.\mathrm{C}_{14}, \mathrm{C}_{16}, \mathrm{C}_{18}\right)$ are synthesized and used as PPDs. Some dispersants, such as Tween $(40,60$, and 80), Span (40, 60, and 80), PAEs, and FAPE (FAPE 5, FAPE 7, and FAPE 9) were selected and compounded together with these terpolymers to improve the cold flow properties of biodiesel-diesel blends. In addition, the depressive effects of these PPDCs and their possible action mechanism were studied.

\section{Material and Methods}

\section{Materials}

Refined waste cooking oil was provided by Shanghai Zhongqi Environment Technology Co., Ltd. (Shanghai). BWCO and terpolymers (RMC- MB-NVP) were prepared in the laboratory. Diesel untreated with other PPDs was obtained from Sinopec Group, Shanghai, China. Other chemicals are available from Tansoole Reagent Co., Ltd. (China), and the following reagents were used: Tween (40,60, and 80), Span (40,60, and 80), PAEs include dimethyl phthalate (DMP), diethyl phthalate (DEP), and dibutyl phthalate (DBP), FAPE (FAPE 5, FAPE 7, and FAPE 9), benzyl alcohol, 1-dodecanol, 1-tetradecanol, 1-hexadecanol, 1-octadecanol, p-toluene sulfonic acid, methacrylic acid, pyrrolidone, hydroquinone, benzoyl peroxide, and toluene.

\section{Production and Characterization of BWCO}

The waste cooking oil and methanol were mixed in a molar ratio of 1:7, and the alkali-catalyzed transesterification reaction was performed at $65 \operatorname{deg} \mathrm{C}$ for $2 \mathrm{~h}$ to invented raw BWCO products. When the reaction was completed, glycerin was precipitated at the bottom of the reactor, and the reaction product was on the upper part and maintained for 10 hours to separate. Subsequently, the crude product was washed with deionized water, rotary evaporated, and dried. Finally, biodiesel was obtained. Furthermore, the composition of biodiesel was analyzed using a Gas Chromatography-Mass Spectrometer (Shimadzu GC-MS QP 2010SE). The operating procedures and parameters of the instrument are shown in the Supporting Information.

\section{Preparation and Characterization of PPDs}

RMC- MB-NVP terpolymers have been produced in the laboratory, and the synthetic processes are shown in the Supporting Information and Fig S1. The structure of RMC- MB-NVP as in this:

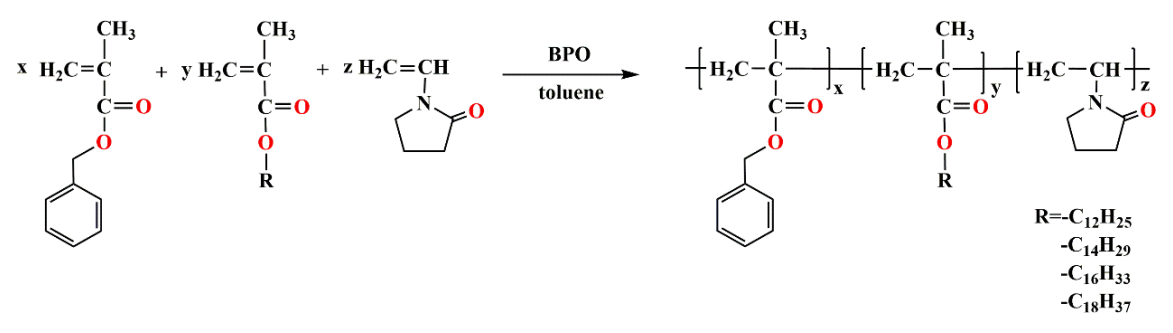

Furthermore, 1H NMR data were recorded using an AVANCE III $500 \mathrm{MHz}$ spectrometer (Switzerland), operating at $500 \mathrm{MHz}$ using a $5 \mathrm{~mm}$ broadband inverse Z-gradient probe in $\mathrm{CDCl}_{3}$ as solvent, as shown in Table S2. FT-IR spectra illustrated in Table S3 are obtained on a Nicolet iN10 Fourier Transform Infrared Spectrometer (USA), which can be scanned 32 times in a scanning range of $400-4000 \mathrm{~cm}^{-1}$.

\section{Preparation of PPDCs}


The PPDCs were prepared by the compound of RMC-MB-NVP terpolymers and some dispersants, such as Span (Span 40, 60, and 80), Tween (Tween 40, 60, and 80), PAEs (DMP, DEP, and DBP) and FAPE (FAPE 5, FAPE 7, and FAPE 9), in the ratios of 0:1, 1:1, 4:1, 8:1, and 1:0, respectively. Then, the PPDCs were added into the prepared biodiesel-diesel blends and sonicated at $30{ }^{\circ} \mathrm{C}$ for $10 \mathrm{~min}$ to ensure complete miscibility. Thereinto, the biodiesel-diesel blends were configured in proportions of 20,40,60, 80, and 100 vol.\% of biodiesels, which labelled as B20, B40, B60, B80 and B100.

\section{Fuel Properties Determination}

The cloud point (CP), cold filter-plugging point (CFPP), and pour point (PP) are crucial indexes of the cold flow properties of biodiesel blends. CP is the temperature at which the wax crystal size increases to 0.5 $\mu \mathrm{m}$, and fuel becomes cloudy at this temperature. CFPP is the maximum temperature at which the $20 \mathrm{~mL}$ test oil fails to pass through the specified strainer at a specified pressure and a certain cooling temperature. $\mathrm{PP}$ is the highest temperature at which fuel, which uses a predetermined certain experimental condition measured oil, loses its fluidity. Therefore, in this study, CP, CFPP, and PP were measured in accordance with standard methods ASTM D2500, ASTM D6371, and ASTM D5949. The measurement is rounded to the nearest whole degree $\left({ }^{\circ} \mathrm{C}\right)$, and three measurements are averaged.

Other fuel properties, such as kinematic viscosity, acid value, density, and flash point, are also important for BWCO and diesel. These fuel physicochemical characteristics are determined using the test methods in Table 1.

\section{Crystallization Behavior and Morphology Observation}

DSC thermal analysis was performed on the biodiesel using a TA Q2000 differential scanning calorimeter (TA Instruments, USA) in the range of 20 to $-60{ }^{\circ} \mathrm{C}$ at a rate of $5.00{ }^{\circ} \mathrm{C} / \mathrm{min}$. Repeat the measurement three times and take the average to reduce the error.

To directly observes the wax crystal formation process, a photomicrograph analysis method can be used. A polarizing optical microscope DM2500 P (Leica Germany) was used to record the wax crystallization behavior of the samples at a temperature decrease rate of $1{ }^{\circ} \mathrm{C} / \mathrm{min}$. Micrographs of all samples were obtained at 100 times magnification.

The rheological properties of the samples from $30{ }^{\circ} \mathrm{C}$ to $-60{ }^{\circ} \mathrm{C}$ were determined by a HAAKE MARS III rheometer (Germany) at a constant shear rate of $5 \mathrm{~s}^{-1}$.

\section{Results and Discussion}

\section{Fuel Properties of BWCO and Biodiesel Blends}

Table S4 shows the percentage of FAME in BWCO. As a consequence, BWCO contained higher levels of saturated fatty acid methyl esters $(38.42 \mathrm{wt} . \%)$ that resulted in its poor cold flow properties.

The fuel properties of biodiesel blends (B20, B40, B60, and B80) are listed in Table 2. As shown in Table 2 , various indicators of biodiesel blends are better than BWCO. Among them, the kinematic viscosity, acid value, and flash point of the blends comply with ASTM D7467. However, when the proportion of biodiesel with high acid value in the blends increases (B60 and B80), the acid value of the biodiesel blends becomes outside the standard range. It is worth mentioning that B20 has the best low-temperature performance, and $\mathrm{CP}$, CFPP, and PP are $-2,-4$ and $-14{ }^{\circ} \mathrm{C}$, respectively. With the increase in BWCO content, the cold flow properties of the blends gradually deteriorate probably because BWCO contains more high melting point unsaturated fatty acid esters. Since the n-alkanes in diesel have a lower melting point, when the proportion of diesel in blends increases, wax crystals are formed at a lower temperature. Therefore, B20 has better cold flow properties than other biodiesel blends.

\section{Depressive Effect of RMC-MB-NVP Terpolymers on Biodiesel Blends}

The CP, CFPP, and PP of $\mathrm{B} 20$ are $-2,-4$ and $-14{ }^{\circ} \mathrm{C}$, respectively. The reduction in $\mathrm{CP}(\Delta \mathrm{CP})$, CFPP $(\Delta \mathrm{CFPP})$, and PP $(\Delta \mathrm{PP})$ of $\mathrm{B} 20$ treated with 1000,2000 , and $3000 \mathrm{ppm}$ RMC-MB-NVP $(\mathrm{R}=12,14,16$, 
18) are shown in Fig 1, and that of B20 treated with 500, 1500, and 2500 ppm RMC-MB-NVP are presented in Fig $\mathrm{S} 4$. The decrease in $\mathrm{CP}$ is the smallest compared with $\triangle \mathrm{PP}$ and $\triangle \mathrm{CFPP}$ under the same conditions.

Fig 1 (e, f) shows that RMC-MB-NVP terpolymers exert higher $\triangle \mathrm{CFPP}$ and $\Delta \mathrm{PP}$ at the dosage of 2000 $\mathrm{ppm}$. At this dosage, the n-alkyl chain length and monomer molar ratio of terpolymers have important effects on the low-temperature performance of biodiesel blends. When the terpolymers have different monomer proportions, with decreasing ratio of the NVP monomer, the depressing effect initially increases and then decreases. When the monomer molar ratio of the terpolymer is 5:1:1, $\triangle$ CFPP have the best reducing effect because the appropriate NVP ratio can increase the solubility of the terpolymer, thereby improving the low-temperature fluidity of biodiesel. When the terpolymers have different side carbon chain lengths, with increasing carbon number in the side chain alkane, the depression effect reveals a trend of initially increasing and then decreasing. $\mathrm{C}_{16} \mathrm{MC}-\mathrm{MB}-\mathrm{NVP}$ terpolymers have the best depressing effect, which can be attributed to the influence of the length of the n-alkyl side chain on CFPP and PP in PPDs. In these experiments, $\mathrm{C}_{16}$ MC-MB-NVP (5:1:1) presented the greatest reduction on the CP, CFPP, and PP of B20 (2, 4 and $\left.9{ }^{\circ} \mathrm{C}\right)$. Thus, 2000 ppm $\mathrm{C}_{16} \mathrm{MC}-\mathrm{MB}-\mathrm{NVP}$ (5:1:1) has the best depressing effect, and B20 has optimal performance compared with other biodiesel blends.

\section{Depressive Effect of the PPDCs on Biodiesel Blends}

To further improve the depressive effects of B20, four dispersants, namely, Span, Tween, PAEs, and FAPE are preferred and combined with $\mathrm{C}_{16} \mathrm{MC}-\mathrm{MB}-\mathrm{NVP}$ terpolymers as PPDCs. The $\triangle \mathrm{CP}, \triangle \mathrm{CFPP}$, and $\triangle \mathrm{PP}$ of B20 treated with 2000 ppm PPDCs are shown in Fig 2.

As shown in Fig 2, the reduction effect of PPDCs on the CFPP and PP of the biodiesel blends is much better than that of a single PPD or dispersant. This finding indicates that dispersants can promote PPD to improve the dispersibility of wax crystals and increase the low temperature flowability of biodiesel. Unfortunately, not all PPDCs could show positive cooperative effect. The [?]CFPP and [?]PP of B20 range between $2^{\sim} 6{ }^{\circ} \mathrm{C}$ and $7^{\sim} 12{ }^{\circ} \mathrm{C}$ when using Tween and Span as dispersants, and between $3^{\sim} 10{ }^{\circ} \mathrm{C}$ and $12^{\sim} 19{ }^{\circ} \mathrm{C}$ when using PAEs and FAPE. In summary, PAEs and FAPE show better effects on improving the low-temperature performance of B20 than Tween and Span. Conversely, these dispersants have small and irregular effect on reducing CP. These experiments can be explained that although dispersants assist PPDs in dispersing the wax crystals and delay their growth time, however, most dispersants have no evident impact on the onset time of wax crystals. In particular, the $\triangle \mathrm{CP}, \triangle \mathrm{CFPP}$, and $\triangle \mathrm{PP}$ of B20 treated with PPDC-DMP (4:1) are 4,8 and 16 ${ }^{\circ} \mathrm{C}$, respectively, at a dosage of $2000 \mathrm{ppm}$. In addition, the depressive effects of PPDC-FAPE 7 (4:1) are 4, 10 and $19{ }^{\circ} \mathrm{C}$ at the identical dosage. It can be explained that PAEs and FAPE act as wax growth arresters, and $\mathrm{C}_{16} \mathrm{MC}-\mathrm{MB}-\mathrm{NVP}$ acts as a nucleating agent. Their combination enhances the dispersibility of PPD to wax crystals. Thus, the wax crystals are more uniform and finely dispersed in the biodiesel blends, thereby improving the low-temperature performance of the fuel.

\section{DSC Analysis}

The energy changes in the phase change process of B20 and combination with PPDs at a low temperature were studied by DSC. Fig 3 and Table 3 show the energetic changes and data in the crystallization of neat B20, B20 with $\mathrm{C}_{16}$ MC-MB-NVP, B20 with PPDC-DMP, and B20 with PPDC-AEO 7. The starting temperature of the peak $\left(\mathrm{T}_{\text {onset }}\right)$ indicates the temperature, in which sedimentation of wax crystals in biodiesel begins, and the solid-liquid phase change energy $(\Delta \mathrm{H})$ reflects the stability of dispersion.

As shown in Fig 3 and Table 3, the [?]H of pure B20 sample is $20.35 \mathrm{~J} / \mathrm{g}$, and the $\mathrm{T}_{\text {onset }}$ of $\mathrm{B} 20$ is $-5.81{ }^{\circ} \mathrm{C}$, which is higher than that of B20 with $\mathrm{C}_{16}$ MC-MB-NVP $\left(-6.05^{\circ} \mathrm{C}\right)$, PPDC-DMP $\left(-6.26{ }^{\circ} \mathrm{C}\right)$ and PPDC-AEO $7\left(-6.81{ }^{\circ} \mathrm{C}\right)$. The peak temperatures of the absorbance peak $\left(\mathrm{T}_{\text {peak }}\right)$ was also reduced from $-6.36{ }^{\circ} \mathrm{C}$ to -6.56 and $-6.65{ }^{\circ} \mathrm{C}$, then to $-7.09{ }^{\circ} \mathrm{C}$. The absolute value of the $\Delta \mathrm{H}$ of $\mathrm{B} 20$ with PPDC-AEO 7 was $18.19 \mathrm{~J} / \mathrm{g}$, which is lower than that of B20 with $\mathrm{C}_{16}$ MC-MB-NVP $(20.27 \mathrm{~J} / \mathrm{g})$ and B20 with PPDC-DMP $(19.94 \mathrm{~J} / \mathrm{g})$. These results suggest that the solid-liquid phase change energy of B20 with PPDC-AEO 7 is smaller, and the biodiesel blends with PPDC-AEO is very stable. 


\section{Rheological Measurements}

Dynamic viscosity, a representation of the flow ability of biodiesel blends, at temperatures from 20 to -40 ${ }^{\circ} \mathrm{C}$, has been depicted in Fig 4 . The figure clearly shows that the viscosity of all samples increases as the temperature decreases.

The figure indicates that the viscosity of the samples did not change remarkably before the temperature reached CFPP. As the temperature reached the inflection point, which is lower than CFPP, the viscosity of the biodiesel blend oil with pure PPDs or PPDCs was remarkably reduced, compared with B20. By contrast, B20 with additives showed a decrease in magnitude of viscosity change compared with pure B20 sample, where PPDCs show a lower magnitude of viscosity change than PPDs. This finding is caused by the addition of PPDs and dispersants in the biodiesel blends, thereby appropriately increasing the dispersibility of wax crystals. As a result, the amount of lager wax crystals in the low-temperature crystallization stage is reduced, thereby decreasing the viscosity of the biodiesel blends.

\section{POM Analysis}

A polarizing optical microscope can be used to observe the wax crystallization behavior and crystal morphology changes. Fig 5 shows the POM of B20 treated or untreated with 2000 ppm PPDs, and dispersants were examined at different temperatures.

As shown in Fig 5 (a), the wax crystals of untreated B20 exhibit feathery or flaky shapes. These larger wax crystals have a strong tendency to aggregate, and they can flow to form a three-dimensional network structure. Thus, B20 loses its fluidity at higher temperatures. Fig 5 (b) shows that the volume of wax crystals is significantly reduced, and the shapes were oval and rod after adding single PPD. However, the wax crystals are unevenly distributed and still tend to aggregate. The reason for this phenomenon is that biodiesel has a different composition from diesel (Rawat et al., 2014; Moser, 2014). B20 is a multicomponent system, which consist of 20 vol.\% biodiesel and 80 vol.\% diesel. The CFPP of FAME is usually higher than that of n-alkanes. Therefore, when components with different CFPP interact, the CFPP temperature of the B20 system will decreases (Magalhães et al., 2019). However, because the structure of pure PPD is more similar to n-alkanes and has better compatibility with diesel, PPD preferentially co-crystallizes with diesel components to form small crystals, and the remaining high CFPP FAME is likely to self-polymerize into larger crystals. Therefore, although PPD delays the precipitation time of wax crystals in B20, the wax crystals still tend to polymerize.

The wax crystals generated when PPDC-DMP (4:1) or PPDC-FAPE7 (4:1) was added to B20, as shown in Fig $5(\mathrm{c}-\mathrm{d})$, and the shape of the wax crystal is sphere-like or long needle-like. However, at the same temperature, the wax crystals produced by PPDC-FAPE7 (4:1) are less than PPDC-DMP (4:1) and are more dispersed, thereby proving that the former has a lower CFPP than the latter. PAEs were selected as wax dispersants because of their highly polar functional groups brought by the two carbonyl groups; accordingly, they achieved surface-active properties and good oil solubility (Magalhães et al., 2008). In addition, FAPEs have larger volume and polarity due to methoxy bonds. This finding can increase the interfacial adsorption capacity of PPDs and shield the nonpolar component of oil, thereby preventing the wax crystals from growing further and exhibiting the best synergy with PPDs. Thus, B20 treated with PPDC-FAPE 7 (4:1) produces uniformly dispersed and smaller wax crystals at low temperatures and exhibits the best cold flow ability.

\section{Effect of PPDC-FAPE 7 on the Fuel Properties of Biodiesel Blends}

In summary, 2000 ppm PPDC-FAPE 7 (4:1) presents the best depressive effect on B20. Table 4 shows the fuel properties of B20 with $2000 \mathrm{ppm}$ PPDC-FAPE 7 (4:1). In the presence of $2000 \mathrm{ppm}$ PPDC-FAPE 7 (4:1), the $\mathrm{CP}$, CFPP, and PP of $\mathrm{B} 20$ are reduced from $-2,-4$, and $-14{ }^{\circ} \mathrm{C}$ to $-6,-14$, and $-33{ }^{\circ} \mathrm{C}$, respectively.

PPDCs imparts excellent cold flow properties to the biodiesel blends and has a slightly affect other properties. The flash point is the lowest temperature at which fuel vapor flashes and burns immediately when it encounters the flame in the air. Fuels with high flash points are less susceptible to fire and are easier to transport. B20 with and without PPDCs has flash points much higher than ASTM D7467, greatly improving 
transportation safety. In addition, the acid value remained unchanged, whereas the kinematic viscosity and density increased slightly. The experimental data satisfied the standard of biodiesel blends (ASTM D7467).

\section{Conclusion}

The presence of dispersants can efficiently enhance the solubility and dispersibility of polymeric PPDs in biodiesel blends, and the PPDCs of RMC-MB-NVP terpolymers combined with the dispersants presented better depressive effects than the single terpolymers. Among them, $\mathrm{C}_{16} \mathrm{MC}-\mathrm{MB}-\mathrm{NVP}$ (5:1:1) combined with FAPE 7 dispersant at 4:1 mass ratio (PPDC-FAPE 7) showed the best synergistic effect, and the CP, CFPP, and PP of B20 treated with 2000 ppm PPDC-FAPE 7 are decreased by 4,10 , and $19{ }^{\circ} \mathrm{C}$, respectively.

POM showed that PPDCs have the property of inhibiting the aggregation of crystals, changing the crystal growth, and reducing the crystal size, which is beneficial for improving the low-temperature performance of fuel. The energy reduction of the solid-liquid phase transition can be observed by DSC analysis, and the viscosity is reduced at the same time. The results presented by the different approach indicated that B20 treated with PPDC-FAPE 7 significantly improves its cold flow properties.

\section{Acknowledgements}

This study was founded by the National Natural Science Foundation of China (Project Number 22008155, 22075183, 21878188 and 21975161), Chenguang Program of Shanghai Education Development Foundation and Shanghai Municipal Education Commission (Project Number 19CG69), Science and Technology Commission of Shanghai Municipality Project (Project Number 18090503800), Shuguang Program of Shanghai Education Development Foundation and Shanghai Municipal Education Commission (Project Number 18SG52), the Talent Development Foundation of Shanghai (Project Number 2018034), Shanghai Gaofeng \& Gaoyuan Project for University Academic Program Development.

\section{Conflict of Interest}

The authors declare that they have no conflict of interest.

\section{Supporting Information}

The GC-MS analysis method of diesel, preparation, and characterization of PPDs, FTIR spectroscopy of $\mathrm{C}_{16} \mathrm{MC}, \mathrm{MB}$ and $\mathrm{C}_{16} \mathrm{MC}-\mathrm{MB}-\mathrm{NVP}, 1 \mathrm{H}$ NMR spectra of $\mathrm{C}_{16} \mathrm{MC}$ and $\mathrm{C}_{16} \mathrm{MC}-\mathrm{MB}-\mathrm{NVP}$.

\section{References}

Altaie, M.A., Janius, R.B., Rashid, U., Taufiq Yap, Y.H., Yunus, R., \& Zakaria, R. (2015) Cold flow and fuel properties of methyl oleate and palm-oil methyl ester blends. Fuel , 160 :238-44.

Biswell, C.B., Catlin, W.E., Froning, J.F., \& Robbins, G.B. (1955) New polymeric dispersants for hydrocarbon systems. Industrial and Engineering Chemistry , 47 :1598-601.

Cao, L., Wang, J., Liu, K., \& Han, S. (2014) Ethyl acetoacetate: a potential bio-based diluent for improving the cold flow properties of biodiesel from waste cooking oil. Applied Energy, 114:18-21.

Cao, L., Wang, J., Liu, C., Chen, Y., Liu, K., \& Han, S. (2014) Ethylene vinyl acetate copolymer: a bio-based cold flow improver for waste cooking oil derived biodiesel blends. Applied Energy ,132 :163-7.

Chiu, C.W., Schumacher, L.G., \& Suppes, G.J. (2004) Impact of cold flow improvers on soybean biodiesel blend. Biomass $\& 3$ Bioenergy ,27 :485-91.

Chastek, T.Q. (2011) Improving cold flow properties of canola-based biodiesel. Biomass 85 Bioenergy , 35 :600-7.

Chen, B., Sun, Y., Fang, J., Wang, J., \& Wu, J. (2010) Effect of cold flow improvers on flow properties of soybean biodiesel. Biomass \& Bioenergy ,34:1309-13. 
Deshmukh, S., \& Bharambe, D.P. (2008) Synthesis of polymeric pour point depressants for Nada crude oil (Gujarat, India) and its impact on oil rheology. Fuel Processing Technology , 89 :227-33.

Feng, L., Zhang, Z., Wang, F., Wang, T., \& Yang, S. (2014) Synthesis and evaluation of alkyl acrylate-vinyl acetate-maleic anhydride terpolymers as cold flow improvers for diesel fuel.Fuel Processing Technology, 118 $: 42-8$.

Giraldo, S.Y., Rios, L.A., \& Suárez N. (2013) Comparison of glycerol ketals, glycerol acetates and branched alcohol-derived fatty esters as cold-flow improvers for palm biodiesel. Fuel , 108:709-14.

Joshi, R. M., Pegg, \& M. J. (2007) Flow properties of biodiesel fuel blends at low temperatures.Fuel , 86 $: 143-51$.

Lemos, B.C., Gilles, V., Gonçalves, G.R., de Castro, E.V.R., Delarmelina, M., \& Carneiro, J.W.M. (2018) Synthesis, structure-activity relationship and evaluation of new non-polymeric chemical additives based on naphthoquinone derivatives as wax precipitation inhibitors and pour point depressants to petroleum.Fuel, $220: 200-9$.

Liu, Y., Xu, G., Zhu, L., Lin, H., Qiu, F., \& Han, S. (2019) Influence of alkyl methacrylate-maleic anhydride1-hexadecene terpolymers and their mixtures with ethylene-vinyl acetate as pour point depressants in diesel fuel.Petroleum Science Technology , 37 :2010-7.

Lin, H., Xie, M., Yin, S., Yang, T., Su, B., \& Chen, F. (2020) Influence of methacrylate-benzyl methacrylate$\mathrm{N}$-vinyl-2-pyrrolidone as pour point depression on cold flow properties of diesel fuel.Energy $\&$ Fuels , 34 :1514-23.

Lv, P., Cheng, Y., Yang, L., Yuan, Z., Li, H., \& Luo, W. (2013) Improving the low temperature flow properties of palm oil biodiesel: Addition of cold flow improver. Fuel Processing Technology, 110:61-4.

Madihalli, C., Sudhakar, H., \& Doble, M. (2016) Mannosylerythritol lipid-A as a pour point depressant for enhancing the low-temperature fluidity of biodiesel and hydrocarbon fuels. Energy $\& 5$ Fuels, 30 :4118-25.

Moser, B.R., \& Vaughn, S.F. (2010) Evaluation of alkyl esters from Camelina sativa oil as biodiesel and as blend components in ultra low-sulfur diesel fuel.Bioresource Technology , 101 :646-53.

Moser, B.R. (2014) Preparation and evaluation of multifunctional branched diesters as fuel property enhancers for biodiesel and petroleum diesel fuels. Energy \&5 Fuels , 28 :3262-70.

Magalhães, A.M.S., Pereira, E., Meirelles, A.J.A., Sampaio, K.A., \& Maximo, G.J. (2019) Proposing blends for improving the cold flow properties of ethylic biodiesel. Fuel , 253 :50-9.

Maithufi, M.N., Joubert, D.J., \& Klumperman, B. (2011) Application of gemini surfactants as diesel fuel wax dispersants. Energy 83 Fuels, 25 :162-71.

Ma, P., Xue, Y., Zhao, W., Lan, G., Hang, Z., \& Liu, F. (2015) Study on the performance mechanism of methacrylate pour point depressant in soybean biodiesel blends. RSC Advances , 5 :90144-9.

Moser, B.R., (2014) Impact of fatty ester composition on low temperature properties of biodiesel-petroleum diesel blends. Fuel ,115:500-6.

Moser, B.R. (2012) Preparation of fatty acid methyl esters from hazelnut, high-oleic peanut and walnut oils and evaluation as biodiesel.Fuel, $92: 231-8$.

Moser, B.R. (2012) Biodiesel from alternative oilseed feedstocks: camelina and field pennycress. Biofuels , 3 :193-209.

Sharafutdinov, I., Stratiev, D., Shishkova, I., Dinkov, R., Batchvarov, A., \& Petkov P. (2012) Cold flow properties and oxidation stability of blends of near zero sulfur diesel from Ural crude oil and FAME from different origin. Fuel, 96 :556-67. 
Soliman, E.A., Elkatory, M.R., Hashem, A.I., \& Ibrahim, H.S. (2018) Synthesis and performance of maleic anhydride copolymers with alkyl linoleate or tetra-esters as pour point depressants for waxy crude oil.Fuel , 211 :535-47.

Soni, H.P., Kiranbala., \& Bharambe, D.P. (2008) Performance-based designing of wax crystal growth inhibitors. Energy \& Fuels, $22: 3930-8$.

Umoruddin, N.E.S., Rosdi, M.R.H., \& Ariffin, A. (2018) Mixed surfactant enabled EVA emulsion for PPD applications. Journal of Dispersion Science and Technology, 40 :361-8.

Vedharaj, S., Vallinayagam, R., Yang, W.M., Chou, S.K., \& Lee, P.S. (2014) Effect of adding 1,4-dioxane with kapok biodiesel on the characteristics of a diesel engine.Applied Energy , 136 :1166-73.

Wang, J., Cao, L., \& Han, S. (2014) Effect of polymeric cold flow improvers on flow properties of biodiesel from waste cooking oil.Fuel, $117: 876-81$.

Wang, J., Zhao, W., Ai, Y., Chen, H., Cao, L., \& Han, S. (2015) Improving the fuel properties of biodiesel via complementary blending with diesel from direct coal liquefaction. RSC Advances , 5 :45575-81.

Xu, G., Xue, Y., Zhao, Z., Lian, X., Lin, H., \& Han, S. (2018) Influence of poly (methacrylate-co-maleic anhydride) pour point depressant with various pendants on low-temperature flowability of diesel fuel. Fuel, $216: 898-907$.

Xue, Y., Zhao, Z., Xu, G., Lian, X., Yang, C., \& Zhao, W. (2016) Effect of poly-alpha-olefin pour point depressant on cold flow properties of waste cooking oil biodiesel blends. Fuel , 184 :110-7.

Xue, Y., Zhao, W., Ma, P., Zhao, Z., Xu, G., \& Yang, C. (2016) Ternary blends of biodiesel with petro-diesel and diesel from direct coal liquefaction for improving the cold flow properties of waste cooking oil biodiesel. Fuel , $177: 46-52$.

Xue, Y., Yang, C., Xu, G., Zhao, Z., Lian, X., \& Sheng, H. (2016) The influence of polymethyl acrylate as a pour point depressant for biodiesel. Energy Sources, Part A-Recovery Utilization and Environmental Effects , $39: 17-22$.

Zheng, W., Wang, S., Liu, J., Meng, F., Li, Y., \& Ma, H. (2014) Synthesis and evaluation of wax dispersant for diesel. Energy \& Fuels, 28 :1896-900.

Zhou, M., He, Y., Lin, H., \& Han, S. (2016) Effect of MC-MA polymer pour point depressants on the flow properties of biodiesel. Energy Sources, Part A-Recovery Utilization and Environmental Effects ,38 :1962-8.

Zhao, Z., Yan, S., Lian, J., Chang, W., Xue, Y., \& He, Z. (2018) A new kind of nanohybrid poly(tetradecyl methyl-acrylate)-graphene oxide as pour point depressant to evaluate the cold flow properties and exhaust gas emissions of diesel fuels. Fuel, 216 :818-25.

\section{Tables}

Table 1 Selected specifications along with fuel properties of BWCO and diesel

\begin{tabular}{llll}
\hline Properties & Test method & BWCO & Diesel \\
\hline $\mathrm{CP}\left({ }^{\circ} \mathrm{C}\right)$ & ASTM D2500 & 7 & -1 \\
$\mathrm{CFPP}\left({ }^{\circ} \mathrm{C}\right)$ & ASTM D6371 & 6 & -2 \\
$\mathrm{PP}\left({ }^{\circ} \mathrm{C}\right)$ & ASTM D5949 & 5 & -12 \\
Kinematic viscosity, $40{ }^{\circ} \mathrm{C}\left(\mathrm{mm}^{2} / \mathrm{s}\right)$ & ASTM D445 & 4.03 & 3.04 \\
Acid value $(\mathrm{mg} \mathrm{KOH} / \mathrm{g})$ & GB/T258 & 0.44 & 1.75 \\
Density, $15{ }^{\circ} \mathrm{C}\left(\mathrm{kg} / \mathrm{m}^{3}\right)$ & SH $/$ T0604 & 863.3 & 811.0 \\
Flash point $\left({ }^{\circ} \mathrm{C}\right)$ & GB $/ \mathrm{T} 261$ & 138 & 79 \\
\hline
\end{tabular}


Table 2 Fuel properties of biodiesel blends

\begin{tabular}{|c|c|c|c|c|c|c|}
\hline Properties & $\begin{array}{l}\text { ASTM } \\
\text { D7467 }\end{array}$ & B20 & B40 & B60 & B80 & B100 \\
\hline $\mathrm{CP}\left({ }^{\circ} \mathrm{C}\right)$ & - & -2 & -2 & 0 & 3 & 7 \\
\hline $\mathrm{CFPP}\left({ }^{\circ} \mathrm{C}\right)$ & - & -4 & -3 & -1 & 2 & 6 \\
\hline $\mathrm{PP}\left({ }^{\circ} \mathrm{C}\right)$ & - & -14 & -8 & -3 & -1 & 5 \\
\hline $\begin{array}{l}\text { Kinematic } \\
\text { viscosity, } 40 \\
{ }^{\circ} \mathrm{C}\left(\mathrm{mm}^{2} / \mathrm{s}\right)\end{array}$ & $1.9-4.1$ & 3.07 & 3.35 & 3.61 & 3.97 & 4.03 \\
\hline $\begin{array}{l}\text { Acid value } \\
(\mathrm{mg} \\
\mathrm{KOH} / \mathrm{g})\end{array}$ & $\max 0.3$ & 0.27 & 0.30 & 0.33 & 0.42 & 0.44 \\
\hline $\begin{array}{l}\text { Density, } 15 \\
{ }^{\circ} \mathrm{C}\left(\mathrm{kg} / \mathrm{m}^{3}\right)\end{array}$ & - & 844.0 & 850.9 & 853.0 & 861.4 & 863.3 \\
\hline $\begin{array}{l}\text { Flash point } \\
\left({ }^{\circ} \mathrm{C}\right)\end{array}$ & $\min 52$ & 116 & 120 & 121 & 126 & 138 \\
\hline
\end{tabular}

Table 3 Data analysis of the DSC curves

\begin{tabular}{lllll}
\hline Sample & $T_{\text {onset }}\left({ }^{\circ} \mathrm{C}\right)$ & $\mathrm{T}_{\text {peak }}\left({ }^{\circ} \mathrm{C}\right)$ & $T_{\text {endset }}\left({ }^{\circ} \mathrm{C}\right)$ & $\boldsymbol{\Delta} \boldsymbol{H}(\Theta / \gamma)$ \\
\hline B20 & -5.81 & -6.36 & 59.22 & 20.35 \\
B20+ C 16 MC-MB-NVP & -6.05 & -6.56 & 59.28 & 20.27 \\
B20+PPDC-DMP (4:1) & -6.26 & -6.65 & 59.64 & 19.94 \\
B20+PPDC-AEO 7 (4:1) & -6.81 & -7.09 & 59.42 & 18.19 \\
\hline
\end{tabular}

Table 4 The fuel properties of B20 with PPDC-FAPE 7

\begin{tabular}{llll}
\hline Properties & ASTM D7467 & B20 & B20+PPDC-FAPE 7 \\
\hline $\mathrm{CP}\left({ }^{\circ} \mathrm{C}\right)$ & - & -2 & -6 \\
$\mathrm{CFPP}\left({ }^{\circ} \mathrm{C}\right)$ & - & -4 & -14 \\
$\mathrm{PP}\left({ }^{\circ} \mathrm{C}\right)$ & - & -14 & -33 \\
Kinematic viscosity, $40{ }^{\circ} \mathrm{C}\left(\mathrm{mm}^{2} / \mathrm{s}\right)$ & $1.9-4.1$ & 3.07 & 3.09 \\
Acid value $(\mathrm{mg} \mathrm{KOH} / \mathrm{g})$ & $\max 0.3$ & 0.27 & 0.27 \\
Density, $15{ }^{\circ} \mathrm{C}\left(\mathrm{kg} / \mathrm{m}^{3}\right)$ & - & 844 & 846 \\
Flash point $\left({ }^{3} \mathrm{C}\right)$ & $\min 52 \min$ & 116 & 118 \\
\hline
\end{tabular}

\section{Figure legends}

Fig 1Effects of $1000 \mathrm{ppm}$ (a, b, and c), $2000 \mathrm{ppm}$ (d, e, and f) and $3000 \mathrm{ppm}$ (g, h, and i) RMC-MB-NVP terpolymers on $\Delta \mathrm{CP}, \triangle \mathrm{CFPP}$, and $\triangle \mathrm{PP}$ of $\mathrm{B} 20$

Fig 2 Effect of 2000 ppm $\mathrm{C}_{16}$ MC-MB-NVP combined with Span, Tween, PAEs, and FAPE dispersants on the $\triangle \mathrm{CP}(\mathrm{a}), \triangle \mathrm{CFPP}(\mathrm{b})$, and $\triangle \mathrm{PP}(\mathrm{c})$ of $\mathrm{B} 20$

Fig 3 DSC traces of during cooling of biodiesel blends without and with PPDs in 2000 ppm

Fig 4Viscosity-temperature curves of biodiesel blends with and without PPDs in a 2000 ppm concentration 
Fig 5 POM images of B20 ( $a_{1}, a_{2}$, and $\left.a_{3}\right)$, B20 with 2000 ppm $C_{16}$ MC-MB-NVP $\left(b_{1}, b_{2}\right.$, and $\left.b_{3}\right)$, B20 with 2000 ppm PPDC-DMP $\left(\mathrm{c}_{1}, \mathrm{c}_{2}\right.$, and $\left.\mathrm{c}_{3}\right)$, and B20 with $2000 \mathrm{ppm}$ PPDC-FAPE $7\left(\mathrm{~d}_{1}, \mathrm{~d}_{2}\right.$, and $\left.\mathrm{d}_{3}\right)$ at $-10{ }^{\circ} \mathrm{C},-15{ }^{\circ} \mathrm{C}$, and $-20{ }^{\circ} \mathrm{C}$

\section{Hosted file}

Figures.pdf available at https://authorea.com/users/365892/articles/485819-effect-of-pourpoint-depressants-combined-with-dispersants-on-the-cold-flow-properties-of-biodieseldiesel-blends 